\title{
Multidimensional factors that influence the intention to practice segregation-at-source of solid
} waste: An empirical study

\author{
Kai Wah Cheng ${ }^{a^{*}}$, Syuhaily Osman ${ }^{a}$, Zuroni Md Jusoh and Jasmine Leby Lau ${ }^{\mathrm{a}}$
}

${ }^{a}$ Department of Resource Management and Consumer Studies, Faculty of Human Ecology, Universiti Putra Malaysia, 43400 UPM Serdang, Selangor, Malaysia

\begin{tabular}{l}
\hline C H R O N I C L E \\
\hline Article history: \\
Received: June 20, 2020 \\
Received in revised format: \\
August 302020 \\
Accepted: September 18, 2020 \\
Available online: \\
September 18,2020 \\
\hline Keywords: \\
Descriptive norm \\
Injunctive norm \\
Egoistic concern \\
Altruistic concern \\
Biospheric concern \\
Intention to practice segregation- \\
at-source of solid waste \\
\hline
\end{tabular}

\section{A B S T R A C T}

Solid waste generation in Malaysia is one of the challenging environmental issues which are often neglected by local households. The main purpose of this research is to ascertain the mediating effect of environmental concerns (i.e., egoistic, altruistic, and biospheric concerns) between households' descriptive norm and injunctive norm to practice the segregation-at-source of solid waste. A total of 400 residents living in townships in nine districts in the state of Selangor were selected via a multistage sampling method. A self-administrated bilingual questionnaire was used to collect the research data. As for the mediation test, the present research found that egoistic concern and altruistic concern mediated the significant relationship between injunctive norm and intention to practice the segregation-at-source of solid waste among the households in Selangor. The present research concludes with research implications and provides several avenues for future research in order to create a comprehensive understanding of the segregation-at-source of solid waste policy among Malaysian citizens.

C 2021 by the authors; licensee Growing Science, Canada

\section{Introduction}

Segregation-at-source of solid waste is the most essential approach (Akil, Foziah, \& Ho, 2017) in many rapidly growing towns and cities in developing countries (Banerjee \& Sarkhel, 2020) to minimize the volume of generated waste before transferring them to disposal sites and landfills (Wang, Tang, Long, Higgitt, He, \& Robinson, 2020). However, household solid waste management (Moh \& Manaf, 2014) is identified as a major obstacle by local authorities in many urban areas globally. Statistically, in 2007, 17000 tones solid waste were produced by Malaysian households every day (Noor, Yusuf, Abba, Abu Hassan, \& Mohd Din, 2013). It is then predicted to grow more than 192.0 percent by 49670 tons per day by the end of 2020 (Ministry of Housing \& Local Government, 2015). Thus, this research aims to address the mediating effect of environmental concerns in discovering the relationship between the subjective norm of a household and the intention to practice the segregation-atsource of solid waste in Selangor, Malaysia. Subjective norm (a perceived influence that others may have) is identified by the convictions of what specific important others think one should do, and how motivated one is to comply with the other (Fishbein, 2008). In other words, the present research assumes that perceived social pressure can be a function of belief that causes an individual to approve or disapprove certain behaviors. In this research, the subjective norm has been further divided into two dimensions namely, descriptive norm and injunctive norm via the Theory of Normative Conduct (Cialdini, Kallgren, \& Reno, 1990).

\footnotetext{
* Corresponding author.

E-mail address: chengkaiwah1991@gmail.com (K.W. Cheng) 
Descriptive norms are one of the social norms in social psychology. Wang, Fan, Zhao, Yang, and Fu (2016) described the descriptive norm as an "appropriate" behavior which is typically demonstrated by important referents of a given unique social setting. The influence of descriptive norms on an individual's behavior is also a classical concern for research in the field of social psychology (Ioannou, Zampetakis, \& Lasaridi, 2013). It has been proven that by telling people about what other people commonly do is an effective way to elicit some changes in certain targeted behavior of a group of individuals, including the pro-environmental behavior (Goh, Ritchie, \& Wang, 2017) and recycling (du Toit, Wagner, \& Fletcher, 2017). There are a few researchers who found that the descriptive norm posits an effect on pro-environmental behavior (Van Cauwenberg, Clarys, De Bourdeaudhuij, Ghekiere, de Geus, Owen, \& Deforche, 2018). Besides, some recommendations have been pointed out for considering descriptive norms in predicting recycling behavior (Eriksson \& Forward, 2011). However, to date, no academic research (Elgaaied-Gambier, Monnot, \& Reniou, 2018) has examined the relationship between descriptive norm, environmental concerns, and the intention to practice the segregation-at-source of solid waste.

Besides the descriptive norm, it is worth noting that no previous research has investigated the injunctive norm in understanding the intention to practice the segregation-at-source of solid waste. Indeed, understanding for whom injunctive norm feedback is informative helps in guiding the local communities (Merrill, Miller, Balestrieri, \& Carey, 2016) informing some pro-environmental behavior. Hence, similar research related to energy-saving (Ertz, Karakas, \& Sarigollu, 2016; Meijer, Catacutan, Sileshi, \& Nieuwenhuis, 2015), excessive drinking (Gronhoj \& Thogersen, 2012; Prince \& Carey, 2010), and green behavior (Johe \& Bhullar, 2016; Wan \& Shen, 2015) have been adopted in this research to fill up the research gap in the literature to further advance the general knowledge about the injunctive norm.

There is no consensual and stable definition of environmental concern (Bouscasse, Joly, \& Bonnel, 2018). Nevertheless, generally, it can be postulated as the general perception of environmental protection (Crosby, Gill, \& Taylor, 1981). Milfont and Gouveia (2006), as well as Yeung (2004) further extended the first definition by explaining environmental concern as a directed state of displeasures, compassion, worries, and emotional, where an individual starts involving himself with thoughts towards ecological matters. Existing literature on environmental concern is still scarce in the research field, and the understanding of environmental concern is still accruing and remaining unclear to the body of knowledge. Notwithstanding, a more complementary way of enriching the existing literature is to derive environmental concern according to the three dimensions proposed by Value-Basis Theory (Stern \& Dietz, 1994): egoistic concern, altruistic concern as well as biospheric concern. Accordingly, this specific variable, in turn, acts as the mediating variable between subjective norm (injunctive norm and descriptive norm) and the intention to practice the segregation-at-source of solid waste in an attempt to provide some useful alternatives in Malaysia's natural environment.

To date, no research has examined the mediating effect of egoistic concern between the descriptive norm as well as the intention to practice the segregation-at-source of solid waste. Hence, the present research views this particular literature gap to potentially contribute to the best body of knowledge in order to enhance the understanding among the studied variables, especially in the domain of solid waste segregation-at-source (Nadlifatin, Lin, Rachmaniati, Persada, and Razif, 2016). On one hand, the descriptive norm is recognized as one of the dimensions of subjective norm under the Focus Theory of Normative Conduct (De Leeuw, Valois, Ajzen, \& Schmidt, 2015; Wang et al., 2016; Ru, Wang, \& Yan, 2018). Descriptive norm has been confirmed as a significant predictor for predicting various pro-environmental behaviors (Pan, Chou, Morrison, Huang, \& Lin, 2018) including green travel intention (Onwezen, Antonides, \& Bartels, 2013; Wang et al., 2016; Shi, Fan, \& Zhao, 2017; Ru et al., 2018), energy conservation (Gockeritz, Schultz, Rendon, Cialdini, Goldstein, \& Griskevicius, 2010; Nolan, Schultz, Cialdini, Goldstein, \& Griskevicius, 2008), and recycling behavior (Collado, Staats, \& Sancho, 2019; Nguyen \& Lobo, 2017), according to existing literature. On the other hand, one of the dimensions of environmental concern under the Value-Basis Theory (Stern \& Dietz, 1994) is called egoistic concern. At the same time, the egoistic concern is relevant for shaping sustainable behaviors (Stern, Dietz, \& Kalof, 1993) as well as enhancing environmental behavior (Wang, Zhang, Cao, $\mathrm{Hu}, \& \mathrm{Yu}, 2019$ ) indirectly (Aman, Harun, \& Hussein, 2012). Consequently, following this reasoning, the present research predicts that egoistic concern is a potential mediating variable to be employed between the descriptive norm and the intention to practice the segregation-at-source of solid waste.

A literature search shows that previous research rarely stresses the mediating effect of altruistic concern in the relationship between the descriptive norm and the intention to practice the segregation-at-source of solid wastes (Ru et al., 2018). Hence, the current research views this condition as one of the research contributions to bridge this particular research gap. Sustainable consumption is driven by altruistic concern, as well as the review of literature, which ensures minimizing side effects of an individual's actions on the environment and society (Papista \& Krystallis, 2013) for other people's concerns. Teng, Wu, and Liu (2015), in particular, deliberated that the altruistic concern had a positive and significant effect on the intention to choose green hotels among consumers. Hence, the present research forecasts that altruistic concern has the potential to act as a mediating variable in this current research.

Given that biospheric concern can illustrate descriptive norms (De Groot, Watt, Steg, Kaizer, \& Farsang, 2012) in nature, the present research further predicts that a consumer with strong biospheric concern is also likely to be motivated by such a prosocial norm. As such, the present research suggests that additional efforts should be made to improve biospheric concern 
among the younger generation so that they are aware of the benefits and importance of pro-environmental behavior. Individuals with a high biospheric level will consider the impact of their actions and try to minimize the adverse effects brought to all living things in the ecosystem. Using this reasoning in the context of current research, the research forecasts that households in Selangor can further develop perceived descriptive norms among members in housing estates so that they have a higher intention to practice the segregation-at-source of solid wastes through biospheric concerns that focus on protecting marine life, animals, birds, and plants (Schultz, 2001).

Current research is assumed to be one of the pioneering studies in investigating the interrelationships among injunctive norms, egoistic concern, and intention to practice the segregation-at-source of solid waste. Interestingly, since injunctive norms can play a role as a crucial motivator of social conduct, Leoniak and Cwalina (2019) stressed that injunctive norms will cause a change in an individual's behavior. Unfortunately, in the context of the segregation-at-source of solid waste, previous literature does not elaborate on the diverse nature of the egoistic concern and descriptive norm (Cheng \& Osman, 2019; De Groot, Abrahamse, \& Jones, 2013; Jaiswal \& Kant, 2018). However, the present research assumes that since the egoistic concern is recognized as one of the crucial precursors of pro-environmental behavior (Stern, 2000), it is relevant for this current research to emphasize on the interaction of injunctive norm and the intention to practice the segregation-at-source of solid waste through the egoistic concern.

Based on the literature review conducted, it was found that previous scholars underestimate the mediating effect of altruistic concern on the relationship between injunctive norm and the intention to practice the segregation-at-source of solid waste. Nevertheless, Poortinga, Steg, and Vlek (2004), Schultz and Zelezny (1999) as well as Vining and Ebero (1992) claimed that there is a positive and significant association between altruistic concern and pro-environmental behavior although their research did not show the existence of a strong relationship. Due to the contradictory results identified in the research mentioned above, the present research predicts that it would be meaningful for the current research to close the research gap by improving the understanding of the indirect effect of altruistic concern and the variables in the current research scope, that is, the intention to practice the segregation-at-source of solid waste among 400 respondents in nine districts in the state of Selangor, Malaysia.

Previous studies have employed biospheric concern as a mediating variable in the research scope of sustainable behavior (Martin \& Czellar, 2017), environmental behavioral intention (Lee, 2011), and conservation (Arnocky, Stroink, \& DeCicco, 2007) but not on the intention to practice the segregation-at-source of solid waste. Hence, the present research points out that the specific mediating effect of the biospheric concern in the context of intention to practice the segregation-at-source of solid wastes remains unclear. Fortunately, biospheric concern has obtained high attention on the pro-environmental behavior research (De Groot et al., 2012; Lee \& Jan, 2015; Nilsson, Hansla, Heiling, Bergstad, \& Martinsson, 2016). Findings have shown that consumers with a high biospheric concern level are commonly more concerned about what happens to the natural environment (De Groot \& Steg, 2010; Stern, 2000), and thus are more focused on how the eco-friendly products purchased work against the interest of nature. Consistent with this notion, Perlaviciute and Steg (2015) further addressed that people with a high biospheric concern level exert a higher likelihood to assign more importance to environmental effects due to various irresponsible human behaviors. Following these lines of reasoning, the present research deducts that there is a relationship between injunctive norms, biospheric concern, and the intention to practice the segregation-at-source of solid waste.

Thereby, based on a series of research issues discussed above, the following research question (a) and hypotheses $\left(\mathrm{H}_{\mathrm{a}} 1-\mathrm{H}_{\mathrm{a}} 6\right)$ are of interest and will be addressed in this research:

a) To what extent do environmental concerns (egoistic concern, altruistic concern as well as a biospheric concern) mediate the significant relationship between a household's subjective norms (descriptive norm as well as the injunctive norm) and the intention to practice the segregation-at-source of solid waste?

$\mathbf{H}_{\mathbf{a}}$ 1. Egoistic concern does mediate the significant relationship between a household's descriptive norm and the intention to practice the segregation-at-source of solid waste.

Ha2. Egoistic concern does mediate the significant relationship between a household's injunctive norm and the intention to practice the segregation-at-source of solid waste.

$\mathbf{H}_{\mathbf{a}}$ 3. Altruistic concern does mediate the significant relationship between a household's descriptive norm and the intention to practice the segregation-at-source of solid waste.

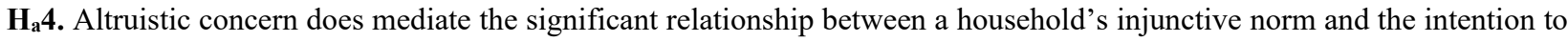
practice the segregation-at-source of solid waste.

$\mathbf{H}_{\mathbf{a}}$ 5. Biospheric concern does mediate the significant relationship between a household's descriptive norm and the intention to practice the segregation-at-source of solid waste. 
$\mathbf{H}_{\mathbf{a}}$ 6. Biospheric concern does mediate the significant relationship between a household's injunctive norm and the intention to practice the segregation-at-source of solid waste.

\section{Materials and methods}

\subsection{Design and procedure}

The current research implemented a quantitative approach under the positivism research paradigm and developed a set of selfadministered bilingual questionnaires as the research instrument. The measurements were adapted and adopted from different sources to examine the key variables in this research. This research also underwent a deduction approach to gain answers to the current research questions and research issues. The number of target respondents (400 respondents) was identified using the sample size determination equation proposed by Yamane (1967).

Selangor was purposely selected as the research location due to several reasons. Firstly, Selangor has the highest population density, the most aggressive economic development, and the greatest urbanization level compared to other states in Malaysia. The households in Selangor also have the highest consumption rate compared to the other states in this country. Apart from that, Selangor has the potential to be transformed into a low carbon city under the Low Carbon Cities 2030 Challenge, a commitment initiated by the Ministry of Energy, Science, Technology, Environment, and Climate Change, and GreenTech Malaysia. Lastly, it is to fulfill the scope of the present research, that is, to cater to the states that have not yet implemented the solid waste segregation-at-source policy. The survey approach was then conducted using a multistage sampling method that represents all households in Selangor, followed by collecting quantitative data from households in Selangor's nine districts using a self-administered bilingual questionnaire that gathers their views on the intention to practice the segregation-atsource of solid waste.

The self-administered bilingual questionnaire and the data collection procedures applied throughout the research were approved by the Universiti Putra Malaysia's Ethics Committee for Research Involving Human Subjects, before the actual data collection. On the actual day of data collection, the bilingual questionnaires were directly distributed through a systematic sampling method by intercepting the households living in the nine selected districts in Selangor regardless of their race, gender, language, or religion. The questionnaires were then collected. Public areas such as hawker centers, recreational parks, wet markets, community centers, mini-libraries, bus stops, and railway stations were the focal points to engage the potential respondents throughout the research. Upon the willingness of the respondents to participate in the research, the researcher was required to confirm the eligibility of the potential respondents using the prepared screening questions. The potential respondents were excluded from the survey when the number of respondents at that particular township had achieved its target. However, when the potential respondents fulfilled all the five screening questions, they were given a pencil and a set of bilingual questionnaires if they expressed their willingness to participate in the survey. Before the respondents responded to the questionnaire, they were briefed on the information stated in the cover letter which also served as the questionnaire's cover page. All the questions in the questionnaire were about the objective and hypotheses of the research. Respondents were requested to respond to each item based on their perceptions and experiences. They were also advised to answer the questions as honestly as possible. Each respondent was given between fifteen and twenty minutes to answer the questionnaire. A souvenir was then given as a token of appreciation to the respondents. The data collection process managed to achieve a hundred percent response rate. A total of four hundred sets of usable bilingual questionnaires were collected after the administration of the survey and analyzed.

\subsection{Participants}

The descriptive analysis of the respondents' particulars regarding their age and sex is outlined in Fig. 1.

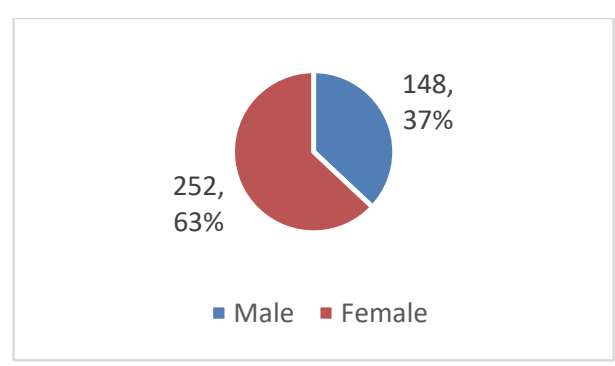

Gender

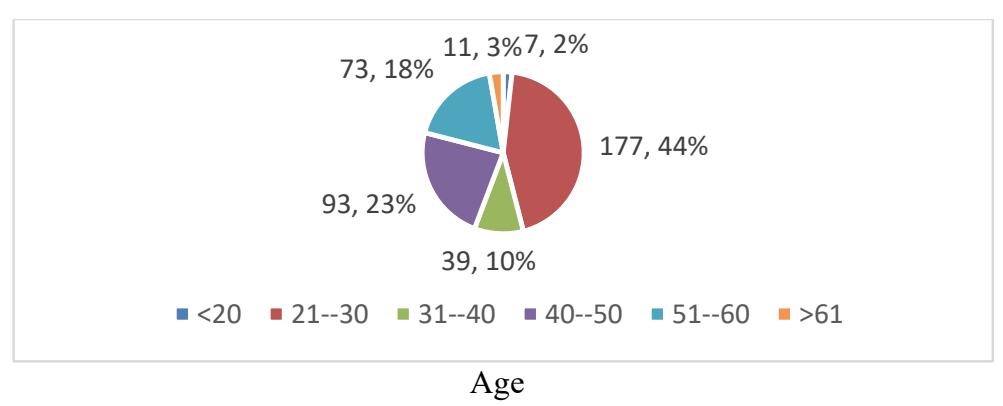

Age

Fig. 1. Distribution of Respondents' Particulars ${ }^{\mathrm{a}}, \mathrm{N}=400$

Note: $\mathrm{N}=$ Total number of respondents; ${ }^{\mathrm{a}}=$ Totals do not sum to 100.0 due to rounding 
The data gathered for this research from the 400 respondents are 37.0 percent male and 63.0 percent female. The respondents' mean age is 37.9 years old, and the median age is 36.5 years old. In this sample, the youngest and the oldest respondents are ages 20 and 78, respectively. 44.3 percent of the respondents are in the 21 to 30 years old age range. There are only seven respondents below 20 years old, while eleven are above 61 years old.

\subsection{Data analysis}

The collected quantitative data were then analyzed using the IBM SPSS Statistics Version 26.0 and SmartPLS Version 3.2.9 software. Both descriptive and inferential statistics were utilized in the data analysis. As for descriptive analysis, IBM SPSS Statistics Version 26.0 was used to describe and summarize the respondents' basic characteristics. Frequency distribution, percentage distribution, measures of central tendency (median) as well as the measure of dispersion (standard deviation) were used to describe and summarize the distribution of the households' demographic information. The Structural Equation Modeling (SEM) technique using the Partial Least Squares (PLS) approach with SmartPLS Version 3.2.9 software had been used in this research to develop and evaluate the research models developed. For this reason, convergent validity was first evaluated via composite reliability, factor loadings, and average variance extracted (AVE) values (Table 1).

Table 1

Assessment of Convergent Validity

\begin{tabular}{|c|c|c|c|c|}
\hline Variable & Item & $\begin{array}{l}\text { Factor Loading } \\
\quad(>0.500)\end{array}$ & $\begin{array}{c}\text { CR } \\
(>0.700)\end{array}$ & $\begin{array}{c}\text { AVE } \\
(>0.500)\end{array}$ \\
\hline \multirow[t]{5}{*}{$\mathrm{DN}$} & B4 & 0.721 & \multirow[t]{5}{*}{0.833} & \multirow[t]{5}{*}{0.503} \\
\hline & B5 & 0.772 & & \\
\hline & B7 & 0.555 & & \\
\hline & B11 & 0.758 & & \\
\hline & $\mathrm{B} 12$ & 0.717 & & \\
\hline \multirow[t]{12}{*}{ IN } & C1 & 0.715 & \multirow[t]{12}{*}{0.943} & \multirow[t]{12}{*}{0.580} \\
\hline & $\mathrm{C} 2$ & 0.728 & & \\
\hline & $\mathrm{C} 3$ & 0.788 & & \\
\hline & $\mathrm{C} 4$ & 0.748 & & \\
\hline & C5 & 0.793 & & \\
\hline & C6 & 0.810 & & \\
\hline & $\mathrm{C} 7$ & 0.738 & & \\
\hline & C8 & 0.789 & & \\
\hline & $\mathrm{C} 9$ & 0.802 & & \\
\hline & $\mathrm{C} 10$ & 0.730 & & \\
\hline & C11 & 0.779 & & \\
\hline & $\mathrm{C} 12$ & 0.705 & & \\
\hline \multirow[t]{4}{*}{$\mathrm{EC}$} & D1 & 0.790 & \multirow[t]{4}{*}{0.891} & \multirow[t]{4}{*}{0.672} \\
\hline & D2 & 0.844 & & \\
\hline & D3 & 0.814 & & \\
\hline & D4 & 0.830 & & \\
\hline \multirow[t]{4}{*}{$\mathrm{AC}$} & D5 & 0.824 & \multirow[t]{4}{*}{0.894} & \multirow[t]{4}{*}{0.678} \\
\hline & D6 & 0.847 & & \\
\hline & D7 & 0.822 & & \\
\hline & D8 & 0.800 & & \\
\hline \multirow[t]{4}{*}{$\mathrm{BC}$} & D9 & 0.791 & \multirow[t]{4}{*}{0.874} & \multirow[t]{4}{*}{0.635} \\
\hline & D10 & 0.857 & & \\
\hline & D11 & 0.818 & & \\
\hline & D12 & 0.714 & & \\
\hline \multirow[t]{8}{*}{ INT } & E1 & 0.627 & \multirow[t]{8}{*}{0.913} & \multirow[t]{8}{*}{0.569} \\
\hline & E2 & 0.840 & & \\
\hline & E3 & 0.761 & & \\
\hline & E4 & 0.794 & & \\
\hline & E5 & 0.750 & & \\
\hline & E6 & 0.722 & & \\
\hline & E7 & 0.747 & & \\
\hline & E8 & 0.776 & & \\
\hline
\end{tabular}

Composite reliability outputs reveal that all variables exceed the satisfactory value of 0.700 (Hair, Black, Babin, \& Anderson, 2013), indicating all variables' internal consistencies as acceptable and reliable for data analysis. Furthermore, AVE values in the present research suggest a sufficient convergent validity of above 0.500 for all variables (Hair et al., 2013). The factor loadings in the model also show that all the items are located beyond the cut-off value at 0.500 (Hair, Hult, Ringle, Sarstedt, \& Thiele, 2017), proving a significant assessment of indicator reliability throughout the research. After confirmation of the convergent validity, cross-loadings, Fornell-Larcker criterion as well as Heterotrait-Monotrait ratios (HTMT) were used to assess discriminant validity, as outlined in Table 2, Table 3, and Table 4, respectively. 
Table 2

Summary of Loadings and Cross-Loadings

\begin{tabular}{|c|c|c|c|c|c|c|}
\hline & $\mathrm{AC}$ & $\mathrm{BC}$ & $\mathrm{DN}$ & $\mathrm{EC}$ & IN & INT \\
\hline B11 & 0.238 & 0.221 & 0.758 & 0.239 & 0.358 & 0.281 \\
\hline B12 & 0.186 & 0.142 & 0.717 & 0.220 & 0.512 & 0.166 \\
\hline B4 & 0.200 & 0.187 & 0.721 & 0.235 & 0.480 & 0.209 \\
\hline B5 & 0.208 & 0.171 & 0.772 & 0.259 & 0.572 & 0.176 \\
\hline B7 & 0.043 & 0.027 & 0.555 & 0.092 & 0.429 & 0.002 \\
\hline $\mathrm{C} 1$ & 0.203 & 0.142 & 0.507 & 0.264 & 0.715 & 0.155 \\
\hline $\mathrm{C} 10$ & 0.238 & 0.211 & 0.469 & 0.315 & 0.730 & 0.265 \\
\hline $\mathrm{C} 11$ & 0.269 & 0.221 & 0.515 & 0.261 & 0.779 & 0.253 \\
\hline $\mathrm{C} 12$ & 0.321 & 0.305 & 0.514 & 0.364 & 0.705 & 0.295 \\
\hline $\mathrm{C} 2$ & 0.234 & 0.161 & 0.440 & 0.253 & 0.728 & 0.209 \\
\hline $\mathrm{C} 3$ & 0.275 & 0.205 & 0.482 & 0.280 & 0.788 & 0.216 \\
\hline $\mathrm{C} 4$ & 0.418 & 0.313 & 0.457 & 0.379 & 0.748 & 0.317 \\
\hline $\mathrm{C} 5$ & 0.360 & 0.279 & 0.428 & 0.300 & 0.793 & 0.313 \\
\hline C6 & 0.398 & 0.293 & 0.505 & 0.368 & 0.810 & 0.333 \\
\hline $\mathrm{C} 7$ & 0.246 & 0.200 & 0.450 & 0.263 & 0.738 & 0.180 \\
\hline $\mathrm{C} 8$ & 0.323 & 0.271 & 0.487 & 0.328 & 0.789 & 0.290 \\
\hline C9 & 0.212 & 0.192 & 0.450 & 0.200 & 0.802 & 0.153 \\
\hline D1 & 0.555 & 0.484 & 0.248 & 0.790 & 0.357 & 0.456 \\
\hline D10 & 0.621 & 0.857 & 0.202 & 0.602 & 0.262 & 0.481 \\
\hline D11 & 0.570 & 0.818 & 0.183 & 0.496 & 0.211 & 0.446 \\
\hline D12 & 0.489 & 0.714 & 0.140 & 0.453 & 0.232 & 0.333 \\
\hline $\mathrm{D} 2$ & 0.653 & 0.541 & 0.261 & 0.844 & 0.305 & 0.529 \\
\hline D3 & 0.554 & 0.539 & 0.258 & 0.814 & 0.318 & 0.429 \\
\hline D4 & 0.674 & 0.607 & 0.281 & 0.830 & 0.352 & 0.555 \\
\hline D5 & 0.824 & 0.580 & 0.275 & 0.667 & 0.384 & 0.530 \\
\hline D6 & 0.847 & 0.601 & 0.261 & 0.641 & 0.328 & 0.547 \\
\hline D7 & 0.822 & 0.608 & 0.184 & 0.550 & 0.300 & 0.553 \\
\hline D8 & 0.800 & 0.621 & 0.216 & 0.610 & 0.315 & 0.536 \\
\hline D9 & 0.637 & 0.791 & 0.257 & 0.554 & 0.315 & 0.476 \\
\hline E1 & 0.477 & 0.409 & 0.353 & 0.481 & 0.439 & 0.627 \\
\hline E2 & 0.582 & 0.482 & 0.231 & 0.531 & 0.257 & 0.840 \\
\hline E3 & 0.549 & 0.476 & 0.229 & 0.488 & 0.301 & 0.761 \\
\hline E4 & 0.427 & 0.358 & 0.142 & 0.395 & 0.158 & 0.794 \\
\hline E5 & 0.423 & 0.325 & 0.154 & 0.394 & 0.181 & 0.750 \\
\hline E6 & 0.418 & 0.367 & 0.131 & 0.368 & 0.138 & 0.722 \\
\hline E7 & 0.481 & 0.409 & 0.255 & 0.498 & 0.309 & 0.747 \\
\hline E8 & 0.557 & 0.454 & 0.229 & 0.455 & 0.252 & 0.776 \\
\hline
\end{tabular}

Note: Bold values are items' loadings which are beyond the threshold value of 0.500 .

$\mathrm{DN}=$ Descriptive norm; $\mathrm{IN}=$ Injunctive norm; $\mathrm{EC}=$ Egoistic concern

$\mathrm{AC}=$ Altruistic concern; $\mathrm{BC}=$ Biospheric concern; INT $=$ Intention to practice segregation-at-

source of solid waste.

Hair et al. (2013) proposed that for the loadings of study variables, the items should be higher than the cross-loadings by at least 0.1 in a bid to show sufficient discriminant validity. As depicted in Table 2, the outer loadings from various indicators on the variable exceed those of every cross-loading with further constructs. Therefore, the cross-loading criterion could be concluded to satisfy the requirements.

Table 3

Summary of Fornell-Larcker Criterion

\begin{tabular}{|c|c|c|c|c|c|c|}
\hline & $\mathrm{AC}$ & $\mathrm{BC}$ & $\mathrm{DN}$ & EC & IN & INT \\
\hline $\mathrm{AC}$ & 0.823 & & & & & \\
\hline $\mathrm{BC}$ & 0.732 & 0.797 & & & & \\
\hline $\mathrm{DN}$ & 0.284 & 0.250 & 0.709 & & & \\
\hline $\mathrm{EC}$ & 0.748 & 0.665 & 0.320 & 0.820 & & \\
\hline IN & 0.402 & 0.321 & 0.625 & 0.406 & 0.761 & \\
\hline INT & 0.658 & 0.552 & 0.293 & 0.606 & 0.346 & 0.754 \\
\hline
\end{tabular}

Note: $\mathrm{DN}=$ Descriptive norm; $\mathrm{IN}=$ Injunctive norm; $\mathrm{EC}=$ Egoistic concern; $\mathrm{AC}=$ Altruistic concern; $\mathrm{BC}=\mathrm{Biospheric}$ concern; $\mathrm{INT}=$ Intention to practice segregation-at-source of solid waste.

Table 3 indicates that the Fornell-Larcker criterion for the $\mathrm{BC}$ is 0.797 . This number is larger than the value of the FornellLarcker criterion in the column of $\mathrm{BC}(0.250,0.665,0.321$, and 0.552$)$ and is also larger than those in the row of $\mathrm{BC}(0.732)$. A similar observation is also made for the variables of DN, IN, EC, AC, and INT (Fornell \& Larcker, 1981). This shows a good discriminant validity, based on the Hair et al. (2017) explanation. Also, all variables have a correlation value of below 0.850 (Awang, 2014). As a result of the Fornell-Larcker criterion, all the variables studied have met their requirements, showing that the variables have discriminant validity. 
Table 4

Summary of Heterotrait-Monotrait Ratios

\begin{tabular}{cccccc}
\hline & AC & BC & DN & EC & \\
\hline AC & & & & & \\
BC & 0.881 & & & & \\
DN & 0.301 & 0.255 & 0.353 & 0.443 & \\
EC & 0.885 & 0.798 & 0.752 & 0.686 & 0.349 \\
IN & 0.431 & 0.349 & 0.291 & 0.633 &
\end{tabular}

Note: $\mathrm{DN}=$ Descriptive norm; IN = Injunctive norm; $\mathrm{EC}=$ Egoistic concern; AC = Altruistic concern; $\mathrm{BC}=\mathrm{Biospheric}$ concern; $\mathrm{INT}=\mathrm{Intention}$ to practice segregation-at-source of solid waste.

HTMT ratios had been applied in this research to test for discriminant validity. It is worth noting that when HTMT ratios are observed to be above the $\mathrm{HTMT}_{0.900}$ value of 0.900 (Gold, Malhotra, \& Segars, 2001), discriminant validity displays certain problems in the data. Nevertheless, Table 4 shows that all of the HTMT ratios are below 0.900, indicating that the variables used in this research are distinct and show adequate discriminant validity.

\subsection{Measurement model evaluation}

Dual-stage analytical procedures (Anderson \& Gerbing, 1988; Hair et al., 2017) which consist of the assessment of measurement and structural models were employed to evaluate the developed research models. The validity of the measurement model was first tested, followed by the testing of the hypothesized mediation outlined in the structural model. Correspondingly, convergent validity and discriminant validity, as well as composite reliability, were assessed to examine the hypothesized measurement model (Gholami, Sulaiman, Ramayah, \& Molla, 2013) before the hypothesized structural model was tested. The hypothesized structural model is meaningless unless the requirement of each empirical measurement is fulfilled in the first place. For that reason, having satisfactory results of the measurement model is compulsory before proceeding to structural model evaluation. As a result of the measurement model assessment, the factor loadings were greater than 0.500 , the composite reliabilities of all variables were also higher than 0.700, and the all AVE values exceeded 0.500 (Hair et al., 2017). The full description of factor loadings, composite reliability, as well as AVE values, are shown in Table 1.

\subsection{Structural model evaluation}

Evaluating the hypothesized structural model includes assessing the computation of beta $(\beta)$ value, $\mathrm{R}^{2}$-value, and the corresponding $t$-values (Hair et al., 2017) via a bootstrapping technique with resampling of 5000 (Hair, Risher, Sarstedt, \& Ringle, 2019). Firstly, the PLS algorithm was used to examine the path analysis (Fig. 1).

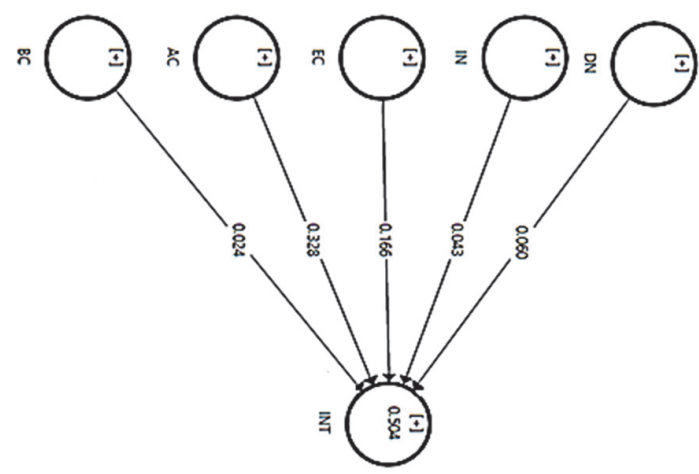

Fig. 2. Structural Model Path Coefficient Results

Note: $\mathrm{DN}=$ Descriptive norm; $\mathrm{IN}=$ Injunctive norm; $\mathrm{EC}=$ Egoistic concern; $\mathrm{AC}=$ Altruistic concern; $\mathrm{BC}=\mathrm{Biospheric}$ concern; INT = Intention to practice segregation-at-source of solid waste.

The results in Fig. 1 show that altruistic concern $(\beta=0.328)$ has the strongest effect on the intention to practice the segregationat-source of solid waste. It is followed by egoistic concern $(\beta=0.166)$, descriptive norm $(\beta=0.060)$, and injunctive norm $(\beta$ $=0.043$ ). It can also be observed that all variables in the structural model have a positive relationship in predicting the intention to practice the segregation-at-source of solid waste since all variables show a positive sign.

A close look in Fig. 2 shows that intention to practice the segregation-at-source of solid waste is the only endogenous variable (one with incoming arrows). For this endogenous variable, the $\mathrm{R}^{2}$-value is recorded at 0.504 , explaining that 50.4 percent of 
the variance in the extent of the intention to practice the segregation-at-source of solid waste could be explained by the model, that was, jointly by the descriptive norm, injunctive norm, egoistic concern, altruistic concern, and biospheric concern. The $\mathrm{R}^{2}$-value justifies an acceptable level of explanatory power, which indicates a significant model (Chin, 1998; Cohen, 2013).

\section{Results}

A direct structural model was constructed to meet the research objective and the hypotheses (Ha1, Ha2, Ha3, Ha4, Ha5, and Ha6) that followed. The bootstrapping technique in the PLS-SEM analysis was employed to analyze the significance of the path within the hypothesized structural model (Fig. 3).

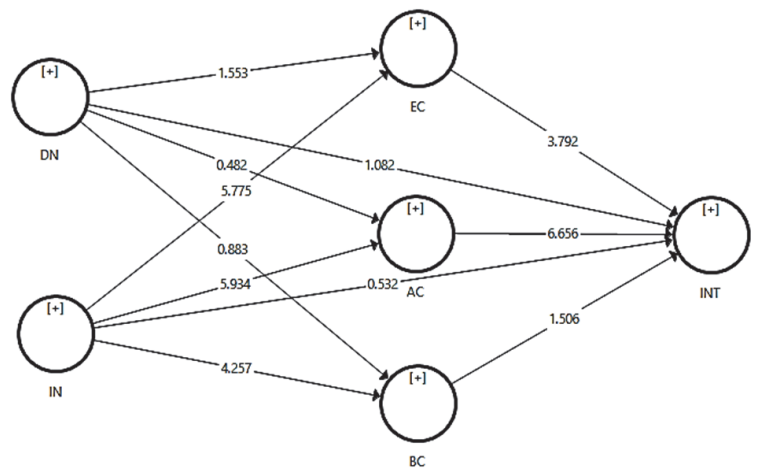

Fig. 3. PLS Bootstrapping for the Mediation of Environmental Concern

Note: $\mathrm{DN}=$ Descriptive norm; IN = Injunctive norm; EC = Egoistic concern; AC = Altruistic concern; $\mathrm{BC}=\mathrm{Biospheric}$ concern; $\mathrm{INT}=\mathrm{Intention}$ to practice segregation-at-source of solid waste.

Using a bootstrap technique with a 5000 resample (Hair et al., 2019), the direct and indirect effects as well as $t$-statistics were analyzed and calculated for the hypothesized structural model. Based on the Fig. 3, in pertinent to the direct effect, it is found that egoistic concern $(\beta=3.792, p=0.000)$ and altruistic concern $(\beta=6.656, p=0.000)$ are positively related to extent of the intention to practice the segregation-at-source of solid waste, whereas descriptive norm $(\beta=1.082, p=0.279)$, injunctive norm $(\beta=0.532, p=0.595)$, and biospheric concern $(\beta=1.506, p=0.132)$ are not. Descriptive norm $(\beta=1.553, p=0.120)$ and injunctive norm $(\beta=5.775, p=0.000)$ are also positively related to extent of egoistic concern. Injunctive norm $(\beta=5.934$, $p=0.000)$ is also positively related to extent of altruistic concern but not for the descriptive norm $(\beta=0.482, p=0.629)$. Lastly, injunctive norm $(\beta=4.257, p=0.000)$ is also positively related to extent of biospheric concern, but not for the descriptive norm $(\beta=0.883, p=0.377)$. The results of indirect effect related to the relevant variables are summarized in Table 5 .

Table 5

PLS Bootstrapping for Mediation of Environmental Concerns between the Independent Variables and Intention to Practice Solid Waste Segregation-at-Source

\begin{tabular}{|c|c|c|c|c|c|c|c|c|}
\hline $\mathrm{H}$ & Relationship & $\mathrm{O}$ & STDEV & t-value & p-value & $\mathrm{LL}$ & UL & Sig. level \\
\hline $\mathrm{H}_{\mathrm{a}} 1$ & $\mathrm{DN} \rightarrow \mathrm{EC} \rightarrow \mathrm{INT}$ & 0.020 & 0.015 & 1.340 & 0.180 & -0.002 & 0.055 & NS \\
\hline $\mathrm{H}_{\mathrm{a}} 2$ & $\mathrm{IN} \rightarrow \mathrm{EC} \rightarrow \mathrm{INT}$ & 0.073 & 0.023 & 3.182 & 0.001 & 0.034 & 0.122 & $* * *$ \\
\hline $\mathrm{H}_{\mathrm{a}} 3$ & $\mathrm{DN} \rightarrow \mathrm{AC} \rightarrow \mathrm{INT}$ & 0.012 & 0.025 & 0.480 & 0.631 & -0.031 & 0.067 & NS \\
\hline $\mathrm{H}_{\mathrm{a}} 4$ & $\mathrm{IN} \rightarrow \mathrm{AC} \rightarrow \mathrm{INT}$ & 0.155 & 0.035 & 4.462 & 0.000 & 0.087 & 0.225 & $* * *$ \\
\hline $\mathrm{H}_{\mathrm{a}} 5$ & $\mathrm{DN} \rightarrow \mathrm{BC} \rightarrow \mathrm{INT}$ & 0.005 & 0.009 & 0.603 & 0.547 & -0.006 & 0.029 & NS \\
\hline $\mathrm{H}_{\mathrm{a}} 6$ & $\mathrm{IN} \rightarrow \mathrm{BC} \rightarrow \mathrm{INT}$ & 0.026 & 0.019 & 1.374 & 0.170 & -0.006 & 0.069 & NS \\
\hline
\end{tabular}

Note: $\mathrm{H}=$ Hypothesis; $\mathrm{O}=$ Original sample; STDEV = Standard deviation; LL = Lower limit; UL = Upper limit; Sig. level = Significance level; DN = Descriptive norm; IN = Injunctive norm; $\mathrm{EC}=$ Egoistic concern; $\mathrm{AC}=$ Altruistic concern; $\mathrm{BC}=\mathrm{Biospheric}$ concern; INT $=$ Intention to practice segregation-at-source of solid waste; $\mathrm{NS}=$ Not supported, $* * *=$ Supported at $p \leq 0.001$ level

According to the outputs displayed in Table 5, four out of nine hypotheses $\left(\mathrm{H}_{\mathrm{a}} 1, \mathrm{H}_{\mathrm{a}} 3, \mathrm{H}_{\mathrm{a}} 5, \mathrm{H}_{\mathrm{a}} 6\right)$ are found to be statistically not supported at $p<0.05$ level after the mediation process involved in the hypothesized structural model. Note that there are only two significant paths in the model which are IN $\rightarrow$ EC $\rightarrow$ INT and IN $\rightarrow$ AC $\rightarrow$ INT for Hypothesis $\mathrm{H}_{\mathrm{a}} 2$ and $\mathrm{H}_{\mathrm{a}} 4$, respectively.

\section{Discussion}

To the best knowledge of the researcher in social sciences, no previous research has applied environmental concern (with its three dimensions) as a mediating variable, either in the Malaysian context or in the research scope of the intention to practice the segregation-at-source of solid waste (Farrow, Grolleau, \& Ibanez, 2017). Therefore, this research represents one of the preliminary attempts in evaluating and discussing these respective elements in detail. This is also the first attempt to apply 
environmental concern (with its three dimensions) as a mediating variable and act as an explanatory link between subjective norms (with its two dimensions) to practice the segregation-at-source of solid waste in Selangor, Malaysia. Consequently, there could be no comparison to identify the variations within the current context.

As shown in Table 6, the standardized mediation effect of egoistic concern to the descriptive norm and the intention to practice the segregation-at-source of solid waste is insignificant at $p<0.05$ level $(t=1.340, p=0.180)$. In other words, the insignificant results suggest the non-existence of mediating effect from the independent variable (descriptive norm) to the dependent variable (intention to practice segregation-at-source of solid waste) via mediating variable (egoistic concern) within the model. Therefore, Hypothesis $\mathrm{H}_{\mathrm{a}} 1$ was not supported. The subsequent hypothesis, Hypothesis $\mathrm{H}_{\mathrm{a}} 2$, suggests that egoistic concern does mediate a significant relationship between injunctive norm and intention to practice the segregation-at-source of solid waste among households living in Selangor. However, the bootstrapping analysis revealed in Table 6 shows that the indirect effect $\beta=21.899\left(5.775^{*} 3.792\right)$ with a $t$-value of 1.340 is significant. Likewise, as indicated by Preacher and Hayes (2008), the indirect effect $21.899,95$ percent Boot CI: [LL $=0.034, \mathrm{UL}=0.122$ ] does not straddle a 0 in between, showing full mediation (Zhao, Lynch Jr, \& Chen, 2010). Thus, the explanation given concludes that the effect of mediation is statistically significant, indicating that the study had supported Hypothesis $\mathrm{H}_{\mathrm{a}} 2$. A closer look at the results portrayed in Table 6 shows that the altruistic concern $(\beta=6.656, p=0.000)$ is positively linked to the extent of intention to practice segregation-at-source of solid waste, and the descriptive norm is not a significant predictor of the extent of intention to practice segregation-atsource of solid waste $(\beta=1.082, p=0.279)$. This indicates that altruistic concern does not mediate the relationship between descriptive norm and intention to practice segregation-at-source of solid waste $(t=0.480, p=0.631)$. Thus, Hypothesis $\mathrm{H}_{\mathrm{a}} 3$ was not supported. The present research also hypothesizes that altruistic concern does mediate the significant relationship between injunctive norm and the intention to practice segregation-at-source of solid waste. To test the fourth hypothesis, the bootstrapping outputs highlight that the direct effect of the injunctive norm $(\beta=5.934, p=0.000)$ is positively linked to the altruistic concern, and the altruistic concern $(\beta=6.656, p=0.000)$ is also positively linked to the extent of the intention to practice the segregation-at-source of solid waste. The bootstrapping analysis proves that the indirect effect $\beta=39.497$ $(5.934 * 6.656)$ with its $t$-value equivalent to 4.462 is significant. Besides, the indirect effect $39.497,95$ percent Boot CI: [LL $=0.087, \mathrm{UL}=0.225]$, and the trend that does not overlap zero between the values (Preacher \& Hayes, 2008), show a mediating effect. Thus, Hypothesis $\mathrm{H}_{a} 4$ was supported by the study. Referring to the rule of thumb of Zhao et al. (2010), it is concluded that the Hypothesis $\mathrm{H}_{a} 4$ postulates a full significant mediating influence of the altruistic concern between injunctive norm and the intention to practice the segregation-at-source of solid waste. The analysis in Table 5 shows that all the tests for direct influences related to Hypothesis $\mathrm{H}_{\mathrm{a}} 5$ are insignificant. Firstly, the descriptive norm $(\beta=0.883, p=0.377)$ is not positively related to biospheric concern. Then biospheric concern $(\beta=1.506, p=0.132)$ is not positively related to the intention to practice the segregation-at-source of solid waste. Next, a bootstrapping procedure as suggested by Hair et al. (2019) has been used to test the mediating effect of biospheric concern in the descriptive norm-to-intention to practice the segregation-atsource of solid waste relationship. The hypothesis testing showed that no mediation occurred in the particular path within the hypothesized structural model. Therefore, Hypothesis $\mathrm{H}_{\mathrm{a}} 5$ was also not supported. This scenario implies that biospheric concern does not mediate the relationship between the descriptive norm and Selangor households' intention to practice the segregation-at-source of solid wastes. Lastly, as portrayed in Fig. 1 and Table 5, the injunctive norm $(\beta=4.257, p=0.000)$ is positively related to the extent of the biospheric concern, whereas the biospheric concern $(\beta=1.506, p=0.132)$ is not a significant predictor of the extent of the intention to practice the segregation-at-source of solid waste. However, after the bootstrapping technique occurred in the hypothesis testing, it can be seen that biospheric concern does not mediate a significant relationship between the injunctive norm of the household with the intention to practice the segregation-at-source of solid wastes $(t=1.374, p=0.170)$. Hence, Hypothesis Ha6 was not supported in this research.

\section{Research implications}

\subsection{Theoretical implication}

The current research has sub-divided environmental concern into its three dimensions independently. Previous studies have also inadequately examined the mediating role of environmental concern in the specific research scope of the intention to practice the segregation-at-source of solid waste. As a result, the current reading materials with regard to the mediating role of egoistic concern, altruistic concern as well as biospheric concern are limited and scarce. Throughout the literature search, the researcher assumed that the environmental concern variable should be measured using multi-dimensional constructs. This is because the individual assessment on the environmental concern variable in a unidimensional way is unable to clarify the environmental concern variable in detail. Hence, by referring to the results of Bootstrapping, egoistic concern $[p=0.001$ ( $p \leq$ $0.001), t=3.182]$ as well as altruistic concern $[p=0.000(p \leq 0.001), t=4.462]$ were found to mediate a significant relationship between injunctive norm and the intention to practice the segregation-at-source of solid waste. Therefore, using the ValueBasis Theory, this current research could significantly highlight the importance of assessing the influencer value of each dimension underpinning the environmental concern and the interrelationships of the variables studied within the research scope. 


\subsection{Policy implication}

The present research is one of the leading research in Malaysia, and the research findings are expected to contribute to the non-governmental organizations and voluntary bodies by building a good and reliable dataset concerning the intention to practice the segregation-at-source of solid waste. Essentially, Waste Management Association of Malaysia, Friends of the Earth Malaysia, Malaysian Nature Society, and Greenpeace Malaysia might potentially gain benefits from this current research and thus work collaboratively to support the solid waste segregation-at-source policy at the social level. Social workers might be able to plan several community activities to assist the local households in segregating their domestic solid waste effectively. Hence, relevant programs should be organized frequently to strengthen the sense of responsibility among households in order to maintain the cleanliness of the environment in Selangor, Malaysia.

\section{Recommendations for future research}

The current research findings point to several avenues for future research. Even though the present sampling of potential respondents was sufficient to determine the perspective for the research conducted in Selangor, the generalization of the results to the whole population in terms of urban and rural areas in Malaysia as a whole is still not guaranteed. This scenario could be due to the perception of the local citizens, availability of local technologies and facilities as well as the local cultures and educational backgrounds. Hence, it is suggested that future research focus on a large-scale geographical boundary in examining the goodness of measures and generalizability of the variables in this present study to different settings of research location to better understand this phenomenon.

The Focus Theory of Normative Conduct and Value-Basis Theory was the backbone theories utilized to develop the present research models. The development of a full model concerning the intention to practice the segregation-at-source of solid waste in this current research was grounded by theoretical supports and proven by empirical results in the literature. Given the complexity of the issues concerning global solid waste, future research could consider including key variables from other different theoretical frameworks, to evaluate to what extent the Focus Theory of Normative Conduct and Value-Basis Theory versus other theories to predict this specific research topic. This initiative, therefore, may guide the researchers to better understand under what kind of circumstances, not just individual variables, but the whole theories, can well predict the intention to practice the segregation-at-source of solid waste.

\section{Conclusion}

The outcomes generated from SmartPLS Version 3.2.9 software proved that out of the six hypotheses, only two significant paths were observed in the hypothesized mediation model. One is that egoistic concern mediates the significant relationship between the injunctive norm of a household and the intention to practice the segregation-at-source of solid waste, and the other, altruistic concern mediates the significant relationship between the injunctive norm of a household and the intention to practice the segregation-at-source solid waste.

\section{Acknowledgment}

The authors would like to thank all the residents, enumerators, and any other parties involved directly or indirectly in the data collection for this research.

\section{References}

Akil, A. M., Foziah, J., \& Ho, C. S. (2017). Households inclination in waste separation program. Asian Journal of Quality of Life, 2(6), 19-30.

Aman, A. L., Harun, A., \& Hussein, Z. (2012). The influence of environmental knowledge and concern on green purchase intention the role of attitude as a mediating variable. British Journal of Arts and Social Sciences, 7(2), 145-167.

Anderson, J. C. \& Gerbing, D. W. (1988). Structural equation modeling in practice: A review and recommended two-step approach. Psychological Bulletin, 103(3), 411.

Arnocky, S., Stroink, M., \& DeCicco, T. (2007). Self-construal predicts environmental concern, cooperation, and conservation. Journal of Environmental Psychology, 27(4), 255-264.

Awang, Z. (2014). Research Methodology and Data Analysis ( $2^{\text {nd }}$ ed.). Universiti Teknologi MARA Shah Alam: UiTM Press.

Banerjee, S. \& Sarkhel, P. (2020). Municipal solid waste management, household and local government participation: A cross country analysis. Journal of Environmental Planning and Management, 63(2), 210-235.

Bouscasse, H., Joly, I., \& Bonnel, P. (2018). How does environmental concern influence mode choice habits? A mediation analysis. Transportation Research Part D: Transport and Environment, 59, 205-222.

Cheng, K. W. \& Osman, S. (2019). The Role of Environmental Education in Waste Segregation-at-Source Behaviour among Households in Putrajaya. Journal of Consumer and Family Economics, 22, 114-136.

Chin, W. W. (1998). The partial least squares approach to structural equation modeling. Modern Methods for Business Research, 295(2), 295-336.

Cialdini, R. B., Kallgren, C. A., \& Reno, R. R. (1990). A focus theory of normative conduct: A theoretical refinement and reevaluation of the role of norms in human behaviour. In Advances in Experimental Social Psychology (Vol. 24, pp. 201-234). Academic Press. 
Cohen, J. (2013). Statistical Power Analysis for the Behavioural Sciences. London: Routledge.

Collado, S., Staats, H., \& Sancho, P. (2019). Normative influences on adolescents' self-reported pro-environmental behaviours: The role of parents and friends. Environment and Behaviour, 51(3), 288-314.

Crosby, L. A., Gill, J. D., \& Taylor, J. R. (1981). Consumer/voter behaviour in the passage of the Michigan container law. Journal of Marketing, 45(2), 19-32.

De Groot, J. I. \& Steg, L. (2010). Relationships between value orientations, self-determined motivational types and pro-environmental behavioural intentions. Journal of Environmental Psychology, 30(4), 368-378.

De Groot, J. I., Abrahamse, W., \& Jones, K. (2013). Persuasive normative messages: The influence of injunctive and personal norms on using free plastic bags. Sustainability, 5(5), 1829-1844.

De Groot, J. I., Watt, A., Steg, L., Kaizer, M., \& Farsang, A. (2012). Environmental values in post-socialist Hungary: Is it useful to distinguish egoistic, altruistic and biospheric values?. Czech Sociological Review, 48(3), 421-441.

De Leeuw, A., Valois, P., Ajzen, I., \& Schmidt, P. (2015). Using the theory of planned behavior to identify key beliefs underlying pro-environmental behaviour in high-school students: Implications for educational interventions. Journal of Environmental Psychology, 42, 128-138.

Du Toit, J., Wagner, C., \& Fletcher, L. (2017). Socio-spatial factors affecting household recycling in townhouses in Pretoria, South Africa. Sustainability, 9(11), 2033.

Elgaaied-Gambier, L., Monnot, E., \& Reniou, F. (2018). Using descriptive norm appeals effectively to promote green behaviour. Journal of Business Research, 82, 179-191.

Eriksson, L. \& Forward, S. E. (2011). Is the intention to travel in a pro-environmental manner and the intention to use the car determined by different factors? Transportation Research Part D: Transport and Environment, 16(5), 372-376.

Ertz, M., Karakas, F., \& Sarigollu, E. (2016). Exploring pro-environmental behaviours of consumers: An analysis of contextual factors, attitude, and behaviours. Journal of Business Research, 69(10), 3971-3980.

Farrow, K., Grolleau, G., \& Ibanez, L. (2017). Social norms and pro-environmental behaviour: A review of the evidence. Ecological Economics, 140, 1-13.

Fishbein, M. (2008). A reasoned action approach to health promotion. Medical Decision Making, 28(6), 834-844.

Fornell, C. \& Larcker, D. F. (1981). Evaluating structural equation models with unobservable variables and measurement error. Journal of Marketing Research, 18(1), 39-50.

Gholami, R., Sulaiman, A. B., Ramayah, T., \& Molla, A. (2013). Senior managers' perception on green information systems (IS) adoption and environmental performance: Results from a field survey. Information and Management, 50(7), 431-438.

Gockeritz, S., Schultz, P. W., Rendon, T., Cialdini, R. B., Goldstein, N. J., \& Griskevicius, V. (2010). Descriptive normative beliefs and conservation behaviour: The moderating roles of personal involvement and injunctive normative beliefs. European Journal of Social Psychology, 40(3), 514-523.

Goh, E., Ritchie, B., \& Wang, J. (2017). Non-compliance in national parks: An extension of the theory of planned behaviour model with pro-environmental values. Tourism Management, 59, 123-127.

Gold, A. H., Malhotra, A., \& Segars, A. H. (2001). Knowledge management: An organisational capabilities perspective. Journal of Management Information Systems, 18(1), 185-214.

Gronhoj, A. \& Thogersen, J. (2012). Action speaks louder than words: The effect of personal attitudes and family norms on adolescents' pro-environmental behaviour. Journal of Economic Psychology, 33(1), 292-302.

Hair, J. F., Hult, G. T. M., Ringle, C. M., Sarstedt, M., \& Thiele, K. O. (2017). Mirror, mirror on the wall: A comparative evaluation of composite-based structural equation modeling methods. Journal of the Academy of Marketing Science, 45(5), 616-632.

Hair, J. F., Risher, J. J., Sarstedt, M., \& Ringle, C. M. (2019). When to use and how to report the results of PLS-SEM. European Business Review, 31(1), 2-24.

Hair, J. F., Black, W. C., Babin, B. J., \& Anderson, R. E. (2013). Multivariate Data Analysis: Pearson New International Edition. New York: Pearson Higher Ed.

Ioannou, T., Zampetakis, L. A., \& Lasaridi, K. (2013). Psychological determinants of household recycling intention in the context of the Theory of Planned Behaviour. Fresenius Environmental Bulletin, 22(7), 2035-2041.

Jaiswal, D. \& Kant, R. (2018). Green purchasing behaviour: A conceptual framework and empirical investigation of Indian consumers. Journal of Retailing and Consumer Services, 41, 60-69.

Johe, M. H. \& Bhullar, N. (2016). To buy or not to buy: The roles of self-identity, attitudes, perceived behavioural control and norms in organic consumerism. Ecological Economics, 128, 99-105.

Lee, K. (2011). The role of media exposure, social exposure and biospheric value orientation in the environmental attitude-intentionbehaviour model in adolescents. Journal of Environmental Psychology, 31(4), 301-308.

Lee, T. H. \& Jan, F. H. (2015). The effects of recreation experience, environmental attitude, and biospheric value on the environmentally responsible behaviour of nature-based tourists. Environmental Management, 56(1), 193-208.

Leoniak, K. J. \& Cwalina, W. (2019). The role of normative prompts and norm support cues in promoting light-switching behaviour: A field study. Journal of Environmental Psychology, 64, 1-11.

Martin, C. \& Czellar, S. (2017). Where do biospheric values come from? A connectedness to nature perspective. Journal of Environmental Psychology, 52, 56-68.

Meijer, S. S., Catacutan, D., Sileshi, G. W., \& Nieuwenhuis, M. (2015). Tree planting by smallholder farmers in Malawi: Using the theory of planned behaviour to examine the relationship between attitudes and behaviour. Journal of Environmental Psychology, 43, 1-12.

Merrill, J. E., Miller, M. B., Balestrieri, S. G., \& Carey, K. B. (2016). Do my peers approve? Interest in injunctive norms feedback delivered online to college student drinkers. Addictive Behaviours, 58, 188-193.

Milfont, T. L. \& Gouveia, V. V. (2006). Time perspective and values: An exploratory study of their relations to environmental attitudes. Journal of Environmental Psychology, 26(1), 72-82. 
Ministry of Housing and Local Government. (2015). Solid Waste Management Lab 2015. Retrieved on July $4^{\text {th }}$, 2020 from https://www.kpkt.gov.my/resources/index/user 1/Attachments/hebahan slider/slaid dapatan makmal.pdf

Moh, Y. C. \& Manaf, L. A. (2014). Overview of household solid waste recycling policy status and challenges in Malaysia. Resources, Conservation and Recycling, 82, 50-61.

Nadlifatin, R., Lin, S. C., Rachmaniati, Y. P., Persada, S. F., \& Razif, M. (2016). A pro-environmental reasoned action model for measuring citizens' intentions regarding ecolabel product usage. Sustainability, 8(11), 1165.

Nilsson, A., Hansla, A., Heiling, J. M., Bergstad, C. J., \& Martinsson, J. (2016). Public acceptability towards environmental policy measures: Value-matching appeals. Environmental Science and Policy, 61, 176-184.

Nolan, J. M., Schultz, P. W., Cialdini, R. B., Goldstein, N. J., \& Griskevicius, V. (2008). Normative social influence is under detected. Personality and Social Psychology Bulletin, 34(7), 913-923.

Noor, Z. Z., Yusuf, R. O., Abba, A. H., Hassan, M. A. A., \& Din, M. F. M. (2013). An overview for energy recovery from municipal solid wastes (MSW) in Malaysia scenario. Renewable and Sustainable Energy Reviews, 20, 378-384.

Onwezen, M. C., Antonides, G., \& Bartels, J. (2013). The Norm Activation Model: An exploration of the functions of anticipated pride and guilt in pro-environmental behaviour. Journal of Economic Psychology, 39, 141-153.

Pan, S. L., Chou, J., Morrison, A. M., Huang, W. S., \& Lin, M. C. (2018). Will the future be greener? The environmental behavioral intentions of university tourism students. Sustainability, 10(3), 634.

Papista, E. \& Krystallis, A. (2013). Investigating the types of value and cost of green brands: Proposition of a conceptual framework. Journal of Business Ethics, 115(1), 75-92.

Perlaviciute, G. \& Steg, L. (2015). The influence of values on evaluations of energy alternatives. Renewable Energy, 77, $259-267$.

Poortinga, W., Steg, L., \& Vlek, C. (2004). Values, environmental concern, and environmental behaviour: A study into household energy use. Environment and Behaviour, 36(1), 70-93.

Preacher, K. J. \& Hayes, A. F. (2008). Asymptotic and resampling strategies for assessing and comparing indirect effects in multiple mediator models. Behaviour Research Methods, 40(3), 879-891.

Prince, M. A. \& Carey, K. B. (2010). The malleability of injunctive norms among college students. Addictive Behaviours, 35(11), 940-947.

Ru, X., Wang, S., \& Yan, S. (2018). Exploring the effects of normative factors and perceived behavioural control on individual's energy-saving intention: An empirical study in eastern China. Resources, Conservation and Recycling, 134, 91-99.

Schultz, P. W. \& Zelezny, L. (1999). Values as predictors of environmental attitudes: Evidence for consistency across 14 countries. Journal of Environmental Psychology, 19(3), 255-265.

Schultz, P. W. (2001). The structure of environmental concern: Concern for self, other people, and the biosphere. Journal of Environmental Psychology, 21(4), 327-339.

Shi, H., Fan, J., \& Zhao, D. (2017). Predicting household PM2. 5-reduction behaviour in Chinese urban areas: An integrative model of Theory of Planned Behaviour and Norm Activation Theory. Journal of Cleaner Production, 145, 64-73.

Stern, P. C. \& Dietz, T. (1994). The value basis of environmental concern. Journal of Social Issues, 50(3), 65-84.

Stern, P. C. (2000). New environmental theories: Toward a coherent theory of environmentally significant behaviour. Journal of Social Issues, 56(3), 407-424.

Stern, P. C., Dietz, T., \& Kalof, L. (1993). Value orientations, gender, and environmental concern. Environment and Behaviour, 25(5), 322-348.

Teng, Y. M., Wu, K. S., \& Liu, H. H. (2015). Integrating altruism and the theory of planned behaviour to predict patronage intention of a green hotel. Journal of Hospitality \& Tourism Research, 39(3), 299-315.

Van Cauwenberg, J., Clarys, P., De Bourdeaudhuij, I., Ghekiere, A., de Geus, B., Owen, N., \& Deforche, B. (2018). Environmental influences on older adults' transportation cycling experiences: A study using bike-along interviews. Landscape and Urban Planning, 169, 37-46.

Vining, J. \& Ebreo, A. (1992). Predicting recycling behavior from global and specific environmental attitudes and changes in recycling opportunities. Journal of Applied Social Psychology, 22(20), 1580-1607.

Wan, C. \& Shen, G. Q. (2015). Encouraging the use of urban green space: The mediating role of attitude, perceived usefulness and perceived behavioural control. Habitat International, 50, 130-139.

Wang, C., Zhang, J., Cao, J., Hu, H., \& Yu, P. (2019). The influence of environmental background on tourists' environmentally responsible behaviour. Journal of Environmental Management, 231, 804-810.

Wang, D., Tang, Y. T., Long, G., Higgitt, D., He, J., \& Robinson, D. (2020). Future improvements on performance of an EU landfill directive driven municipal solid waste management for a city in England. Waste Management, 102, 452-463.

Wang, S., Fan, J., Zhao, D., Yang, S., \& Fu, Y. (2016). Predicting consumers' intention to adopt hybrid electric vehicles: Using an extended version of the theory of planned behaviour model. Transportation, 43(1), 123-143.

Yamane, T. (1967). Elementary Sampling Theory. New Jersey: Prentice Hall.

Yeung, S. P. M. (2004). Teaching approaches in geography and students' environmental attitudes. Environmentalist, 24(2), $101-117$.

Zhao, X., Lynch Jr, J. G., \& Chen, Q. (2010). Reconsidering Baron and Kenny: Myths and truths about mediation analysis. Journal of Consumer Research, 37(2), 197-206.

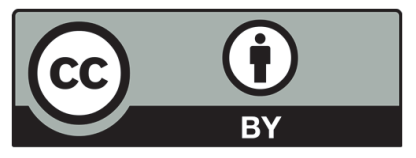

(C) 2020 by the authors; licensee Growing Science, Canada. This is an open access article distributed under the terms and conditions of the Creative Commons Attribution (CC-BY) license (http://creativecommons.org/licenses/by/4.0/). 